\title{
Surgical correction of congenital anomalies in a neonatal lamb: a case report
}

\author{
Z.T. Abd-Almaseeh, A.H. Allawi and F.M. Mohammed \\ Department of Surgery and Theriogenology, College of Veterinary Medicine, University of Mosul, Mosul, Iraq
}

\begin{abstract}
A newborn male lamb 2 days age brought at surgical Department of Veterinary Teaching Hospital - University of Mosul with a history of no defecation and urination. Depend on the clinical, physical and ultrasonographic examinations, the condition was diagnosed as different congenital anomalies of urogenital system (absence of penis, urethra and the scrotal raphae was abnormally prominent, dividing the scrotal sac into two halves, each one with a testicle) associated with atresia ani et recti. Surgical corrections of these different congenital anomalies performed with colostomy and cystostomy operation as emergency case. The animal dies after the second operative day. This paper report a new type of different congenital anomalies in a newborn lamb did not mentioned in other literature yet and the surgical correction adopted for the anomalies.
\end{abstract}

Keywords: Lamb; Scrotum ; Penis; Urethra; Atresia ani.

Available online at http://www.vetmedmosul.org/ijvs

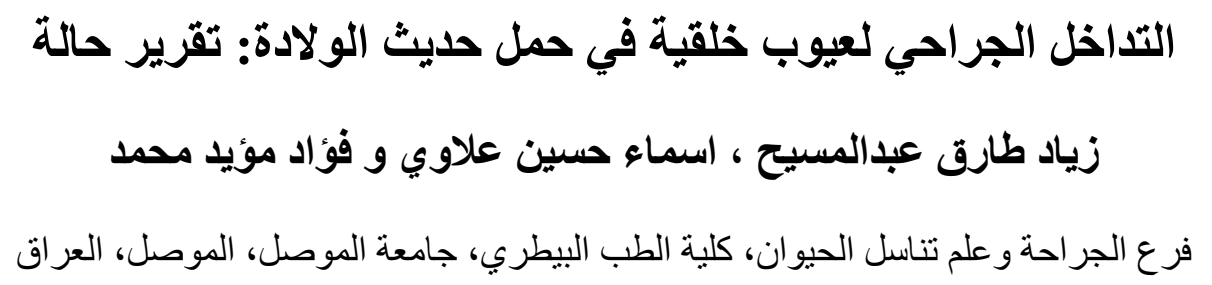

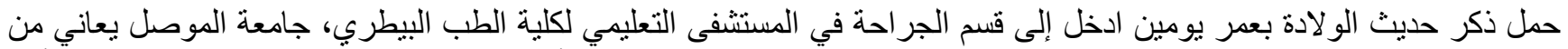

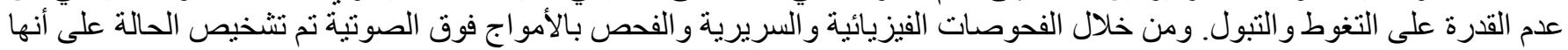

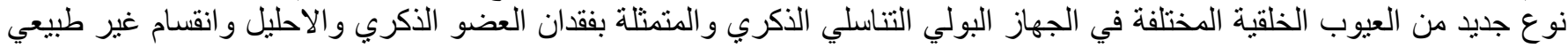

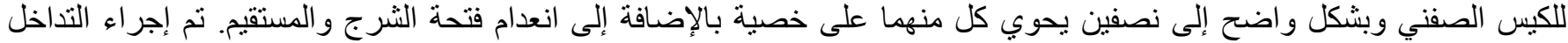

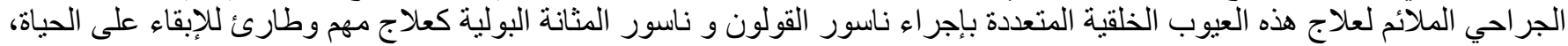

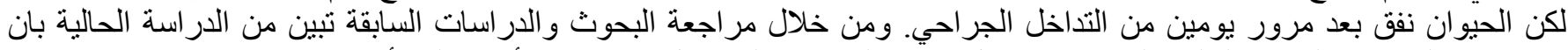

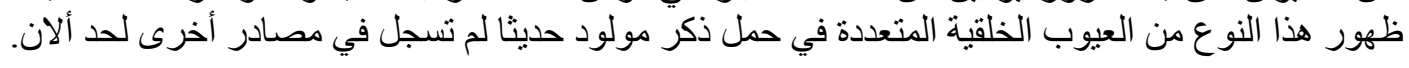

\section{Introduction}

Abnormalities of structures that present at birth are obviously congenital defects; some anomalies may be acquired during fetal development while others may be inherited (1-3). The most frequently anomalies of urogenital system in animals are urethral atresia, polycystic kidney, persistent urachus, ectopic ureter, rupture of the urinary bladder, tersexes (intersex disorders hermaphrodite and pseudohermaphrodite), gonadal hypoplasia (small testes or ovaries), persistent penile frenulun, cryptochidism, prominent scrotal raphae and hypospodias (3-8), which is one of the most common birth defect in animal (it is imperfect closure of external male urethra (9).

Imperforated anus has been reported in several breed of animal and it is more common among male than female although the etiology and causal genetic and environmental factors of anorectal malformations remain poorly understood and unknown $(10,11)$. It may occur alone or together with other abnormalities of digestive system or 
another structure in the body animal such as atresia ani and recti, atresia ani-recti with atresia coli and atresia ani with absence of tail (12-14). Absence of external structure of male urogenital system with atresia ani et-recti does not reported in farm animals. The present paper reports a new type of different congenital anomalies in a lamb include; absence of the penis, urethra, scrotal anomaly associated with atresia ani et-recti.

\section{History and Observation}

A two days old male lamb brought to surgical department of Veterinary Teaching Hospital - University of Mosul. The $5.5 \mathrm{~kg}$ lamb delivered naturally and was suckling and playing alert. The farmer observed that the lamb has shown no defecation and micturation because absence of anal opening as well as absence of penis and urethra. The lamb subjected to detailed clinical examination which revealed clear absence of penis with its skin sheath and prepuce and urethral orifice opening as well as no bulging of the anal region upon straining or during manual abdominal compression, there was neither anal opening nor bulge at the anal site even with hand pressure on the distended abdomen, suggestive of atresia ani et-recti (Figure 1). The other remarkable finding that noticed was abnormal prominent of the scrotal raphae, dividing the scrotal sac into two halves, each one with a testicle (Figure 2). The ultrasonographic examination of the lamb's abdomen revealed a very tense urinary bladder (due to the lamb had not voided urine since 2 days) and accumulation of gases and fluid (resulting in non-passage of muconium). The exploratory laparotomy finding normal urinary bladder with normal right and left ureters (Figure 3).

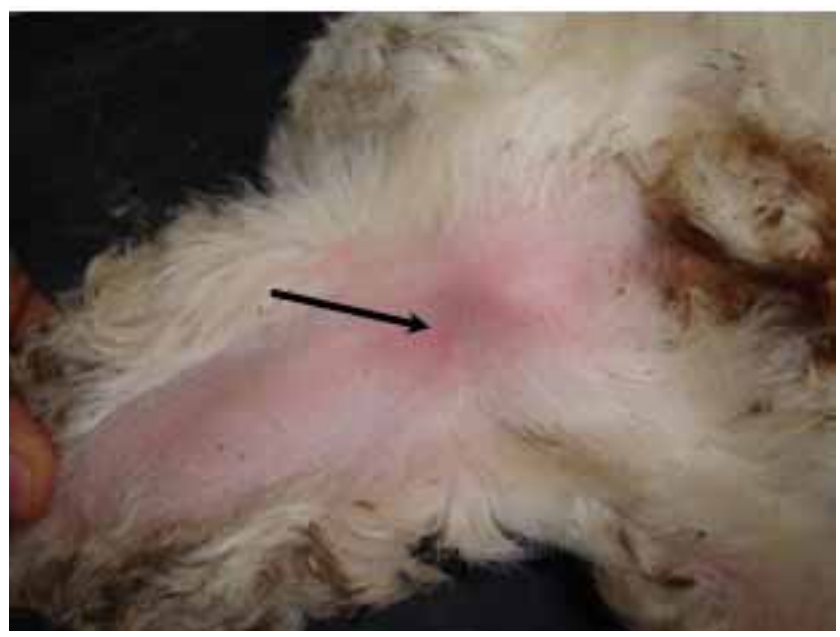

Figure 1: Shown the site of atresia ani et recti (arrow) in a new born lamb.

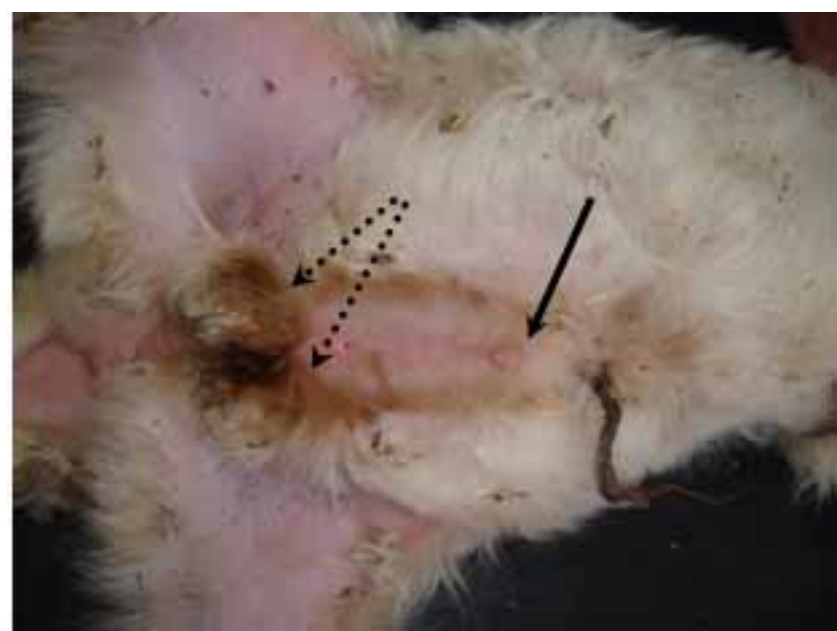

Figure 2: Shown absence of penis, prepuce, urethral opening (single continuous arrow), and the scrotal raphae was abnormally prominent, dividing the secrotal sac into two halves, each one with a testicle (double interrupted arraow).

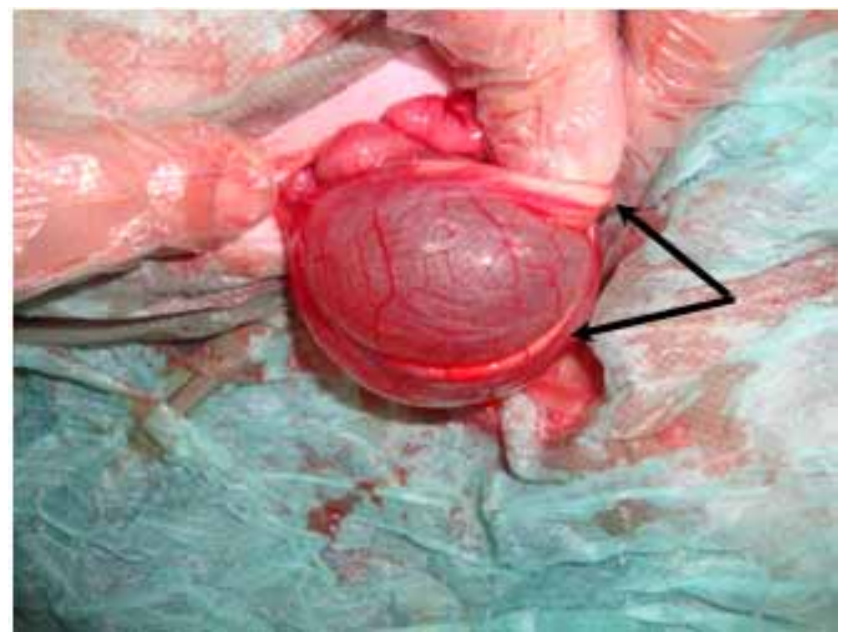

Figure 3: Shown the normal urinary bladder with normal right and left ureters (double arrow) in a new born lamb.

\section{Treatment}

The lamb laid in dorsal recumbence and the ventral abdomen from umbilical region to the scrotal sac was prepared for aseptic surgery. Local anesthetic (Lidoocaine $\mathrm{HCl} 1 \%$ solution) infiltrated in a linear fashion just above the intended line of incision.

A left paramedian laparotomy performed through the skin and abdominal muscles and penetrating the peritoneal cavity carefully by making a stab incision in peritoneum to avoid puncture of the distended urinary bladder (U.B.) (Figure 4). Complete aspiration and evacuation of about $150 \mathrm{ml}$ of urine from the U.B. using a $50 \mathrm{ml}$ disposable 
syringe with 22 gauge needle (Figure 5), a very small punch opening incision performed in a less vascular area through the wall of empty U.B. and far enough from the near ureters. This new created opening was sutured with subcutaneous tissues using No. 1 chromic catgut in an interrupted suturing pattern (marsupialization), after that using an elastic tube that fixed at the cystostomy opening (new created urinary opening) by applying of two interrupted stitches using silk No. 1 to maintain the opening during healing process (Figure 6).

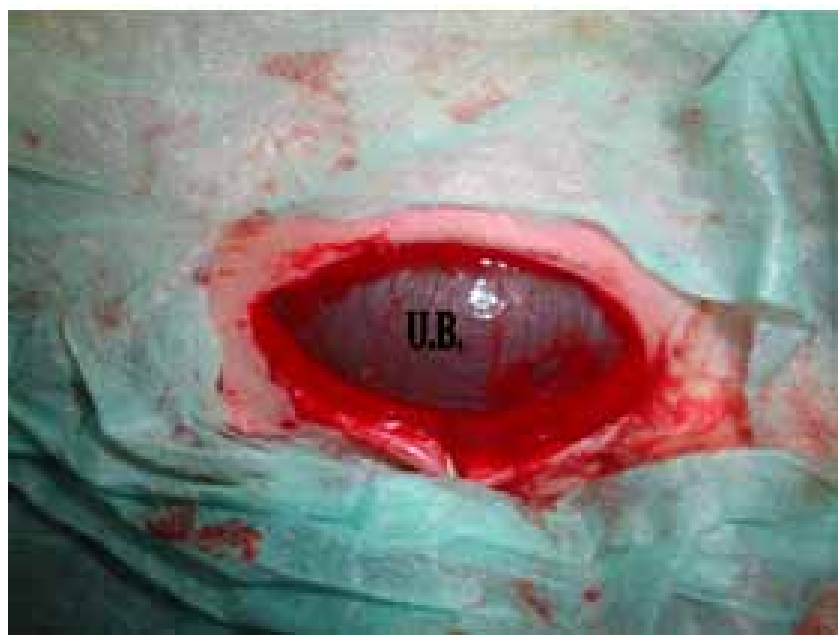

Figure 4: Shown distended urinary bladder (UB) after the left paramedian laparotomy.

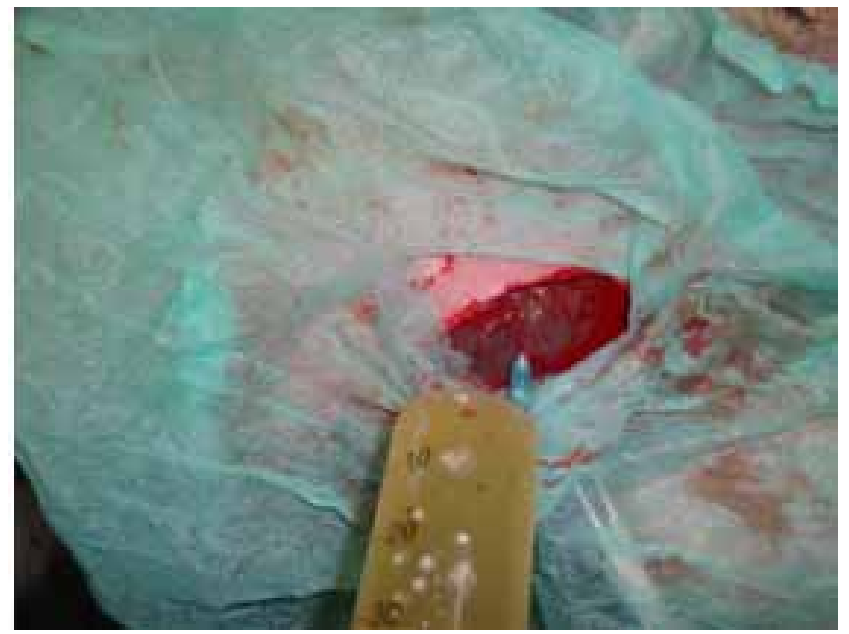

Figure 5: Shown aspiration and evacuation of urine from the U.B. using a $50 \mathrm{ml}$ disposable syringe with 22 gauge needle.

Atresia ani et recti was treated by performing a colostomy. The distal part of the colon could be located via the same left approach. A segment of colon was pulling toward the anterior end of the laparotomy incision. The incision sutured with simple interrupted pattern for the abdominal muscles and skin using No.1 chromic catgut and No.1 silk, respectively and leaving the anterior end of laparotomy incision for the colostomy opening. The colon edges sutured circumferentially to the skin to perform a colostomy, and the colon sutured to the leaving caudal part of the laparotomy wound, using No.1 Silk in an interrupted suturing pattern in a circumferential fashion (Figure 6). Finally, the wall of colon fixed with skin, then the muconium and gases evacuated freely through the created colostomy opening (Figure 7).

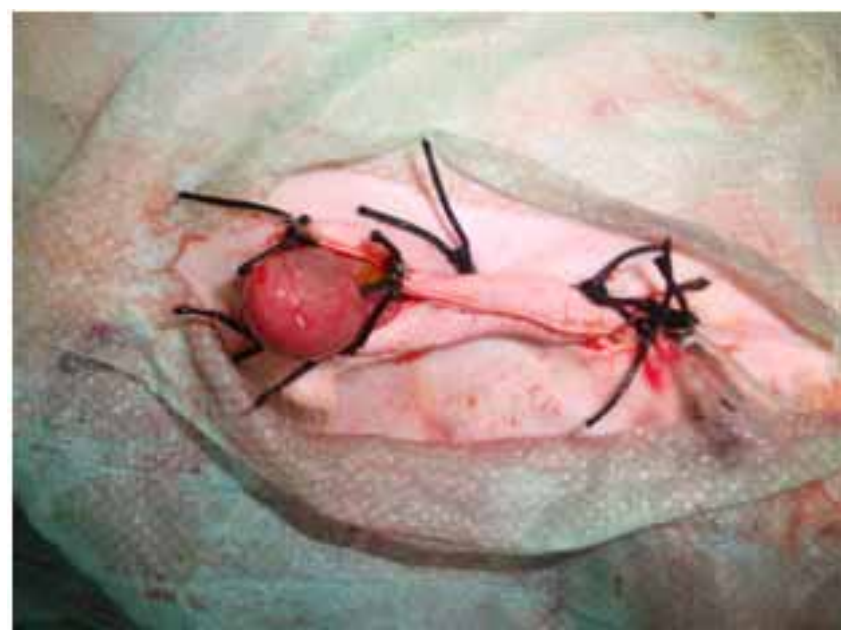

Figure 6: Shown cystostomy opening with the maintained elastic tube for voided urine and circumferential fashion suturing of colon with skin for colostomy,

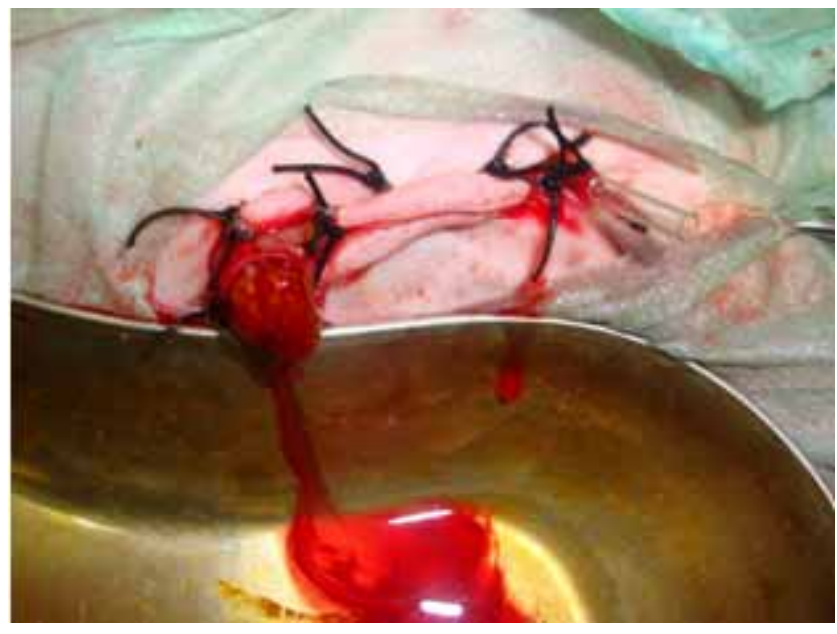

Figure 7: Shown free evacuated of muconium and gases after excision of circular piece of colon to perform a colostomy. 


\section{Results and discussion}

Congenital defects, abnormalities of structure or function present at birth may be cause by genetic, environmental factors or combination of both, but generally, it considered as a congenital deformity that may be cause by extra or intra uterine factor resulting defects in androgen metabolism and / or androgen receptors (1). In the present study atresia ani et recti, absence of urethra with penis and prominent scrotal raphae was noted in the same animal. Intestinal atresia has been report as congenital defect in all species of domestic animal (15). Failure of the membrane to become perforated, failure of the bond to become canalized and interruption of the foetal blood supply to the anus may lead to atresia ani or atresia ani et recti (12). The principle clinical signs of such cases are depression, anorexia and abdominal distension; the time of onset for clinical signs may vary from 1-8 day (16). Colostomy is surgical procedure used for surgical correction of the atresia ani et recti, this operation have been used by another authors for treatment of intestinal atresia such as atresia ani et recti and atresia coli (13). In the other hand the development of the external male genitalia is a complex process involving genital programming, cell differentiation, hormonal signaling, enzyme activity and tissue remodeling. Disturbances in these processes may lead to disruption of the fusion of the urogenital fold at different sites along the urogenital tract, environmental toxicant and xenoestrogens acting during fetal life have been partly implicated in an increasing incidence of reproductive tract abnormalities $(4,12,17)$, but in the present study the urogenital tract (urethra and penis) was not developed, the animal has no urethra nor penis and the urinary system ended at urinary bladder which distended due to accumulation of urine (Figure 4), so cystostomy was made for surgical correction, although the surgical correction is not recommended when the anomaly coexists with other malformations (8). Prominent scrotal raphae did not treat in this animal because it is not acute condition. However, in the present study the newborn lamb suffered from increase of body temperature, restless, inability to suckling and finally died 2 day after surgery, the age at presentation has never been associated with survival rate (7) even with the increased degree of peritonitis. The long-term survival rate of surgically treated animals depends largely on the site of intestinal atresia and surgical technique used, and the type of congenital anomalies.
Developmental defects may be lethal, semi-lethal, or compatible with life causing aesthetic defects or having no effect on the animal $(1,18)$. Surgical intervention is the best choice for the treatment in such acute abdominal discomfort and congenital abnormalities. This paper reports a new type of congenital anomalies in a newborn lamb did not mentioned in other literature yet and the surgical correction adopted for these anomalies.

\section{References}

1. Johnson JL, Leipold TT, Hdson DB. Prominent congenital defect in Nebraska beef cattle. Breeding and Reproduction. 1985; 4(7): 1-8.

2. Simon S, William BJ, Rao GD. Congenital malformations in ruminants and its surgical management. Vet World. 2011; 3(3): 118119.

3. Blood D, Radostits OM. In Veterinary Medicine, 7th ed. Baillien and Tindall Company. London, UK. 1989; pp. 98-408.

4. Sakhaee E, Azari O. Hypospadia in goats. Iran J Vet Res. 2009; 10: 328.

5. Al-Ani FK, Khamas WA, AL-Qudah KM. Occurrence of congenital anomalies in shami breed goats 211 cases investigated in 19 herds. Small Rumin Res. 1998; 28. 225-232.

6. Ahmeti U, Kolgegi S, Arifi H. Clinical dilemmas and surgical treatment of peroscrotal, scrotal and perineal hypospodias. Bosn J Bas Med Scie. 2009; 9(3): 229-234.

7. Kumar H, Sharma AK, Dass L, Anand A. Atresia ani with scrotal anomaly in a goat. Vet World. 2009; 2(2): 68.

8. Sharma S, Jit S. The urinary system. In:. Tyagi RPS, Jit S, editors Rumin Surgery. New Delhi, India. 2002; pp. 272.

9. Azani O, Sakhaee E, Emad L. Permanent urethrostomy for treatment of caprine hypospadia. Am J Anim Vet Scie. 2010; 5(2): 107-110.

10. Simon S, William J, Rao G. Congenital malformations in ruminants and its surgical management. Vet World. 2010;3(3): 118-119.

11. Van Der Putte SC. Normal and abnormal development of the anorectum. J Ped Surg. 1986; 21: 434-440.

12. Veena P, Snakar P, Suresh R. Congenital absence of tail with atresia ani and hypospodias in a kid- Acase report. J Advance Vet Res. 2011; 1: 76-78.

13. Aziz S, Mohammadi R, Mohammadpour R. Surgical repair and management of congenital intestinal atresia in 68 calves. Vet Surg. 2010; 39: 115-120

14. Ohanen M, Yoshida C, Nishibori M. A case of freemartin with atresia recti and ani in Japanese black calf. Anim Reprod Scie. 2005; 85 (3-4): 193-199.

15. Van Der Gass I, Tibboel D. Intestinal atresia and stenosis in animals: a report of 34 cases. Vet Path. 2001; 17: 565-574.

16. Smith DF., Durcharmu NG, Fubini SL, Donawick WJ, Erb HN. Clinical management and surgical repair of atresia coli in calves(19771988). J Am Vet Med Assoc.1991; 199: 1185-1190.

17. Baskin LS, Himes K, Colborn T. Hypospadias and endocrine disruption: is there a connection ?Environ Health Persp. 2001; 109: 1175-1183.

18. Martin WB, and Aitken LD. Disease of sheep. 2nd Ed. Black Well Scientific Publications. Oxford, UK. 1991; pp. 383. 